\title{
Hadträge.
}

Daß Bedjfelbolle unjerer Beit, worauf im Bortwort hingetwiejen worden

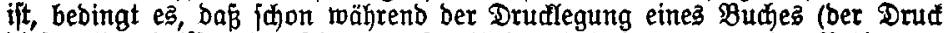
biejes Brumbriffes hat jajon im Frühjahr 1923 begonnen) eine Reihe von

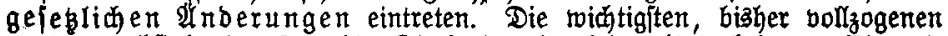
werben nadjteheno aufgezählt. Die Folgezeit wirb weitere bringen; (Einzel. Geiten eines Lehrbuds unterliegen beratt rajher laberholung, bem find Lehrer unt Lernender gemeinfam ausgejegt.

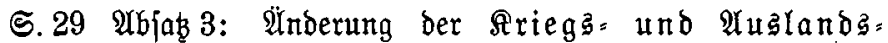

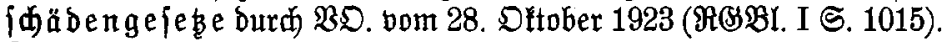

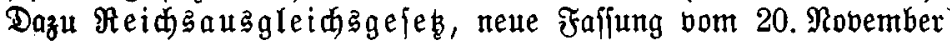

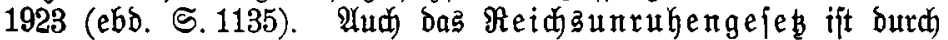

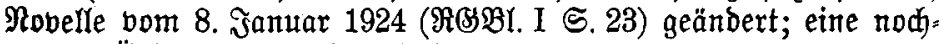
malige itnderung foll beboritehen.

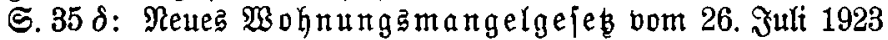

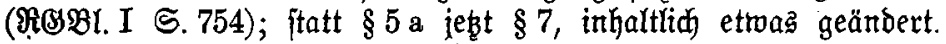

S. 46 3iff. 1: Das lebte Brotberiorgungsgefes ift nut=

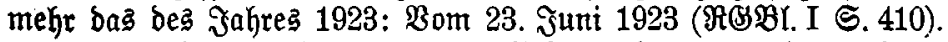

S. 48 oben: Ginzugetreten: (Sejeb über wertbeftänoige

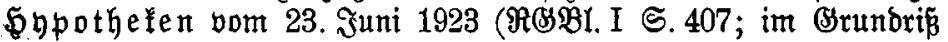
vgl. bazu S. 377).

S. 48 Biff. $5 \alpha$ : Bgl. aud Sejeb über bie Sidheritellung von

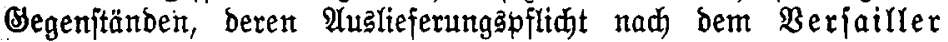

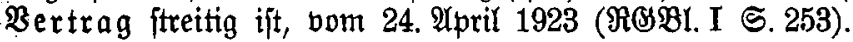

S. 72 Biff. 1: S. Nahtrag zu S. 46.

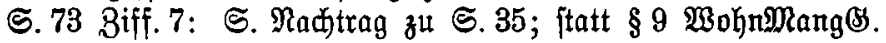
jest $\$ .6$.

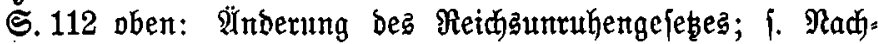
trag z̆ ङ. 29.

S. 114 oben: S. Nautrag zu 73.

S. 127 oben: Die Inge hat jich nah übermindung ber (selb. entwertung wieder verjobett.

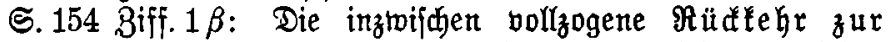

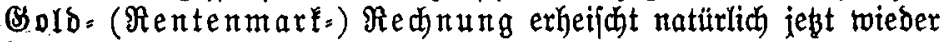
fitrenge Eintilitung Der Dreimarforenze.

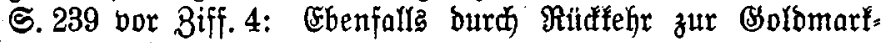
rechinung verifioben.

S. 244 b: Das Brunderwerbjteuergefeb hat einige linbe: rungen burd bie ztweite Steuernotberoronung vom 19. Dezember 1923

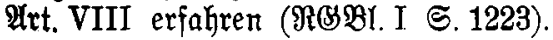


S. 249 Biff. 3: Bgl. aud Beamten:Sieblungageroronung

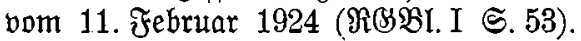

S. 327b und c: Das 3 toangsmietrecht ift in ber llmgeftaltung

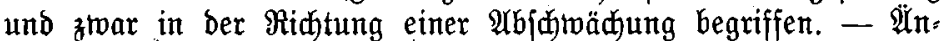

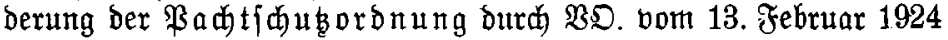

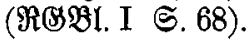

S. 328 a 3: Neue Fafjung des Wolynungmmangelgejebes vom

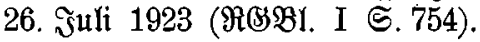

S. $374 \mathrm{~d}$ : Trobbem die Belbentwertung leit Finführung der Rentenmarł an Bebeutung berloren hat, twird ihr $\mathfrak{B i r f e n}$ gerabe im Bereid bes Shypothefentwefens als hift orifales Faftum noch auf lange hinaus beadtentwert bleiben. S. aud jogleidh Nadtrag z̆ S. 375.

S. 375 e: Die britte Steuernotberoronung bom 14. Febr.

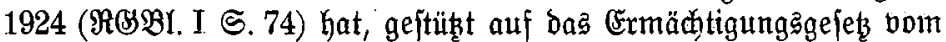
8. Dezember 1923, Die Frage ber Sypothefenaufrertung mit einem fharfen biftatorifhen Shnitt zu löfen verjudht. Der Seit= gebanfe ijt: Bereits zurüfógezahlte Sypothelen gelten als endgültig exledigt, nod beitehende werden mit 15 v. $\mathfrak{f}$. ihres Nominaltwerts abgefunben. Ein ganzer Sranz von Streitfragen hat fich aber bereits

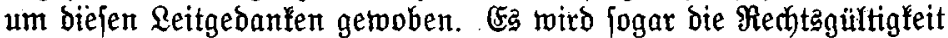
ber ganzen britten SteuerNot:SD. bejtritten. 2uch ift ez nicht aus=

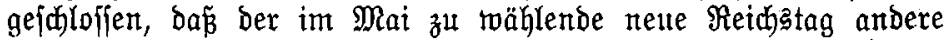
Brandjäbe aufitellt, wodurd freilid bie mübjam gefdaffene "Stabi= lijierung" injerer Wirtjøaftżberhältnifie ernjtlich gefährbet werben fönnte.

\section{Derwei Iungen.}

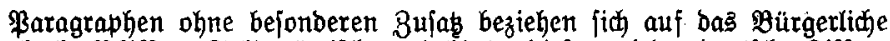

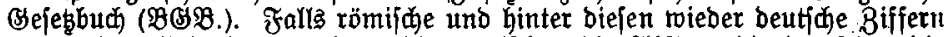

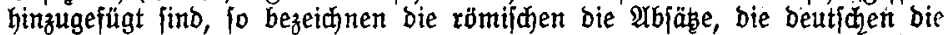
eimzelnen Säke innerhalb Deș betreffenben \$aragraphen. Ilnbere Bsejebc

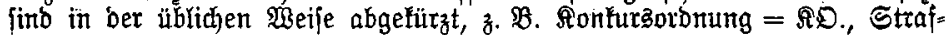

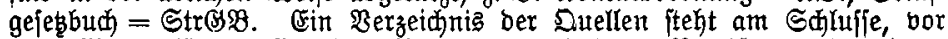
bem Wortregifter. Eifrige senubung beiber Regifter toirb bem Sermenden empiohlen.

Fnnerhalb bes Brunbriffes twirb meilt nă den Seitenzahlen berwiefen. Wo autnahmatweije nach Der ßaragrapheneinteilung zitiert witb, ift, um

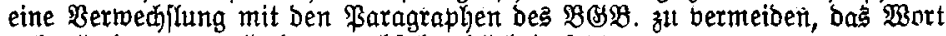
"oben" ober "unten" poer "nadfolgend" beigejegt.

D̈fter witb aud auf allbere Brumbriffe, $\mathfrak{z}$. $\mathfrak{B}$. Den bes artgemeinen Teils boer bes Sdulbredts Bezug genommen. Dem follte ber Rermenbe, wenn

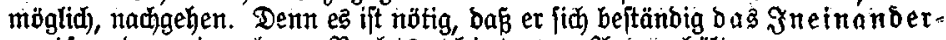
greifen ber eirzelren Rectsgebiete vor Mugen bält. 